\title{
Extractivismo minero en Bogotá: contribuciones para el debate desde la historia ambiental urbana
}

Recepción: 16 de abril del 2020 - Evaluación: 18 de noviembre de 2021 • Aprobación: 29 de noviembre de 2021

\begin{abstract}
Resumen: El presente artículo tiene la finalidad de conocer cuáles son los conflictos socioambientales generados por el extractivismo minero en la ciudad de Bogotá. Para tal fin se proponen tres apartados: en el primero se abordan algunas comprensiones conceptuales y metodológicas que presenta el autor sobre la historia ambiental urbana (HAU), la cual permite problematizar y complejizar los territorios construidos socialmente, estableciendo un contrapunteo con algunos referentes de la geografía urbana. En el segundo se analiza la herencia minera a partir de tres periodos de la HAU de Bogotá: 1) periodo colonial y la alfarería; 2) la modernización de la ciudad y los chircales; y 3 ) el crecimiento urbano y la presencia de los parques minero-industriales (PMI), haciendo un énfasis especial en los PMI del sur de la ciudad desde la óptica del extractivismo para proceder a analizar las dinámicas económicas detrás de la minería y los efectos ambientales. En el tercer apartado se presentan las conclusiones y reflexiones finales.
\end{abstract}

Palabras clave: conflicto, extractivismo, historia ambiental, minería, territorio, urbano.

Para citar: Gauta Blanco, B. S. (2022). Extractivismo minero en Bogotá: contribuciones para el debate desde la historia ambiental urbana. Perspectiva Geográfica, 27(1), 69-85. https://doi. org/10.19053/01233769.11103 


\title{
Mining extractivism in Bogotá: contributions to the debate from the perspective of urban environmental history
}

\begin{abstract}
Summary: The present article aims to understand the socio-environmental conflicts caused by mining extractivism in the city of Bogotá. For this purpose, three sections are proposed: the first deals with some conceptual and methodological understandings presented by the author on urban environmental history (UAH), which allows the problematization and complexification of socially constructed territories, setting up a counterpoint with some references of urban geography. The second section analyses the mining heritage from three historical periods of the UAH of Bogotá: 1) the colonial period and pottery; 2) the modernization of the city and the mining areas; 3) urban growth and the presence of mining-industrial parks (MIP), placing special emphasis on the MIP in the south of the city from the perspective of extractivism to proceed to analyze the economic dynamics behind mining and its environmental effects. The third section presents the conclusions.
\end{abstract}

Keywords: conflict, extractivism, environmental history, mining, territory, urban.

\section{Extrativismo mineiro em Bogotá: contribuições para o debate a partir da história ambiental urbana}

\begin{abstract}
Resumo: O presente artigo tem a finalidade de conhecer quais são os conflitos socioambientais gerados pelo extrativismo mineiro na cidade de Bogotá. Para o efeito, são propostos três parágrafos: no primeiro, são abordadas algumas compreensões conceptuais e metodológicas apresentadas pelo autor sobre a História Ambiental Urbana (HAU), a qual permite problematizar e se tornar complexo os territórios construídos socialmente, estabelecendo um contraponto com alguns referentes da geografia urbana. No segundo analisa-se a herança mineira a partir de três períodos da HAU de Bogotá: 1) período colonial e a olaria; 2) a modernização da cidade e as áreas de mineração; 3) crescimento urbano e a presença dos parques mineiro-industriais (PMI), dando um especial ênfase nos PMI do sul da cidade desde a óptica do extrativismo para proceder a analisar as dinâmicas econômicas por trás da mineração e os efeitos ambientais. No terceiro parágrafo apresentam-se as conclusões.
\end{abstract}

Palavras-chave: conflito, extrativismo, história ambiental, mineração, território, urbano. 


\section{Introducción}

Bogotá tendrá que ser redescubierta en las huellas de la gente que fue capaz de hacer de su periferia, como en el caso de Ciudad Bolivar, una ciudad posible para vivir, al sembrar en los cerros no solo casas sino también cerca de un millón de vidas.

Arturo Alape

La historia ambiental urbana (HAU), como campo del conocimiento que se encuentra en permanente proceso de configuración, tiene como propósito comprender las relaciones multicausales que establece el ser humano con la naturaleza y los territorios construidos socialmente, recurriendo a herramientas de análisis de la geografía, la historia, las ciencias sociales y naturales y los demás campos del conocimiento que se preocupan por dichas relaciones desde perspectivas inter o transdisciplinares del ámbito urbano desde la perspectiva ambiental.

Es importante mencionar que la HAU es relativamente reciente y se encuentra en un momento prolífico a nivel conceptual, temático y metodológico, en donde centros y grupos de investigación se han ido posicionando con el paso de los años; como es el caso de la Sociedad Latinoamericana y Caribeña de Historia Ambiental (SOLCHA). Así mismo, investigadores independientes y organizaciones sociales han encontrado en la HAU un campo de trabajo sólido para problematizar las realidades territoriales a nivel local, nacional y regional.

En ese marco de reflexión, el presente artículo tiene como objetivo contribuir al debate académico y político desde el estudio de caso de la minería en la ciudad de Bogotá retomando algunas herramientas metodológicas de la historia ambiental, como la definición de periodizaciones y necesidades ambientales y urbanas.

El estudio de los conflictos socioambientales generados por la minería fue seleccionado por varias razones, ya que el crecimiento urbano de Bogotá y la sabana en los últimos quinquenios ha generado el aumento en la demanda de materias primas para ser procesadas y suministrar ladrillos, gravas, arenas, arcillas y demás derivados pétreos para la construcción de viviendas y vías en la región, los cuales son suministrados por diferentes empresas que operan en la ciudad y los municipios circunvecinos y genera cambios sustanciales en el paisaje y los ecosistemas de los territorios.

Dentro de los principales hallazgos se destaca la noción de herencia minera en Bogotá, la cual hace referencia a cuatro momentos diferentes en la historia de la ciudad en donde la actividad minera ha sido utilizada para suplir las necesidades urbanísticas propias del momento de expansión y crecimiento: 1) alfarería y periodo colonial; 2) modernización de la ciudad y los chircales; y 3) el crecimiento urbano y la presencia de los parques minero-industriales (PMI), haciendo un énfasis especial en los PMI del sur de la ciudad desde la óptica del extractivismo para proceder a analizar las dinámicas económicas detrás de la minería y sus efectos ambientales.

A nivel conceptual se propone la categoría de extractivismo minero para analizar las dinámicas económicas, ambientales y legales presentes en Bogotá, en donde el Estado, tanto en sus niveles nacionales como subnacionales, tiene un particular interés en la producción periférica a gran escala debido a los ingresos fiscales y las dinámicas de crecimiento económico se puedan generar sin importar los riesgos ni las afectaciones ambientales y sociales, privilegiando así una visión desarrollista y neoliberal en donde se antepone la acumulación de capital, razón por la cual la pregunta central que orienta la investigación radica en identificar cuáles son los conflictos socioambientales generados por el extractivismo minero en la ciudad de Bogotá.

Finalmente, es importante fortalecer los debates y las investigaciones sobre la ciudad y su relación con el ambiente porque se encuentran en disputa las formas de ordenar y relacionarnos con el territorio de manera sustentable, con miras hacia los retos que debe asumir la ciudad para para adaptarse al cambio climático en los próximos años. 


\section{Contrapunteo entre historia ambiental y geografía urbana: elementos para el debate}

La historia ambiental (HA) surge tras la necesidad de comprender el deterioro ambiental que empezó a vivir el mundo desde las décadas de los setenta y los ochenta, en donde se generaron importantes conflictos sociales y ambientales en torno al uso de los recursos naturales en contextos urbanos y rurales. Si bien es cierto que los embriones de la HA surgieron en Europa y Estados Unidos, en los últimos años América Latina (especialmente México, Colombia y Brasil) ha venido desarrollando procesos de investigación de gran importancia en torno a la HA de nuestro continente que han permitido ampliar las realidades urbanas y rurales desde categorías y rutas metodológicas propias, así como retomar las investigaciones geográficas, históricas, ecológicas y sociológicas que se han construido en torno a los asuntos ambientales. Sánchez-Calderón y Blanc (2019) plantean que

Las condiciones de desigualdad económica de la región han encontrado un nuevo empujón en los últimos años con la progresiva implantación de programas políticos y económicos ligados al neoextractivismo, modelo bajo el cual pareciera reeditarse un periodo de inserción en las dinámicas globales basado en la explotación intensa de los ecosistemas del continente, con el agravamiento de las condiciones de vida de muchas poblaciones (p. 8).

Estas condiciones permiten el surgimiento de nuevos retos en materia socioambiental en el continente, en donde poblaciones indígenas, afro, campesinas y urbanas se han visto gravemente afectadas. Resulta interesante que, en el amplio espectro de trabajo de la HA, el escenario urbano y la realidad de la ciudad latinoamericana se ha ido constituyendo en un asunto de relevancia investigativa y política. $\mathrm{Al}$ respecto, Molano (2019) plantea la importancia de reconocer el contexto histórico en el cual emerge este campo de trabajo, marcado por las tensiones geopolíticas que atravesaba el mundo entre el espectro capitalista y el socialista de la segunda mitad del siglo xx:

Desde la década de 1960 la sensibilidad histórica por los problemas ambientales venía produciendo lo que algunos autores denominaron el giro ambiental de las ciencias sociales, que dio origen a la ecología política, la antropología y la historia ambiental (Molano, 2019, p. 378).

Dentro de los enfoques de trabajo y los problemas que ha ido estudiando la historia ambiental urbana (HAU) se destacan: el acceso a la vivienda, la justicia ambiental, el crecimiento de la ciudad, la movilidad, la sostenibilidad ambiental, el aprovechamiento de las basuras y las fronteras urbano-rurales, problemáticas que han venido tomando importancia en las agendas políticas y de investigación. En esa medida, urge la necesidad de problematizar las ciudades de Colombia desde las perspectivas históricas y ambientales. En esta oportunidad, se aborda la minería en Bogotá desde el diálogo entre la HAU y la geografía urbana debido a los conflictos socioambientales generados por el extractivismo minero. En esa medida, se plantea que

La historia ambiental de la ciudad es un campo débilmente desarrollado. La mayoría de las investigaciones históricas sobre Bogotá abordan los problemas urbanos, la arquitectura, el espacio físico creado por el hombre, pero es muy poco el análisis sobre la relación entre el entorno urbano y ecosistemas naturales, o sobre ciudad y entorno natural, para citar sólo dos aspectos (Preciado et al., 2005, p. 17).

Algunos de los aportes de la HAU radican en el uso de enfoques y perspectivas interdisciplinares y transdisciplinares para dar respuesta a los vacíos analíticos de los temas ambientales urbanos, contribuyendo de esa manera a una mirada holística, amplia y compleja. Otra de las contribuciones son sus ejes temáticos, los cuales son múltiples, dinámicos y acordes a las necesidades de las poblaciones y los territorios, poniendo en diálogo abierto los elementos temporales, espaciales y sociales para brindar nuevas interpretaciones 
a los problemas socioambientales del escenario urbano como el crecimiento urbano, el cambio del uso del suelo, las transformaciones en los ecosistemas y el aprovisionamiento de servicios públicos, entre otros.

En esa corriente, Preciado, Leal y Almanza (2005) han realizado una contribución de gran importancia para comprender el desarrollo urbano y social que ha tenido la ciudad de Bogotá. Como producto de sus disertaciones tenemos el libro Historia ambiental de Bogotá siglo XX: elementos históricos para la formulación del medio ambiente urbano, en el cual los autores logran realizar periodizaciones sobre las dinámicas urbanas propias de la ciudad de Bogotá desde mediados del siglo XIX, en donde se destacan las siguientes necesidades ambientales y territoriales:

- Crecimiento demográfico acelerado de la ciudad, lo cual implica una creciente demanda de bienes y servicios.

- Problemas de salud pública como resultado de la ausencia de alcantarillado, suministro y calidad de agua potable y manejo de residuos.

- Déficit de vivienda.

- Falta de políticas públicas para ordenar el territorio en torno a los ecosistemas.

Los anteriores problemas urbanos han sido permanentes en la historia de Bogotá e indudablemente cada uno responde a un momento histórico específico del proceso de configuración de la ciudad unido a la aparición de necesidades y ausencias en la población. Sin embargo, surge la pregunta: ¿cuál es la relación de las demandas sociales sobre el ambiente y el territorio? Algunas apreciaciones que se pueden deducir es que la ausencia de vivienda y alcantarillado, el cambio del uso del suelo y el manejo de residuos han generado una pérdida gradual y continua de algunos valores ambientales, como la capa vegetal, biodiversidad, pérdida de los cuerpos hídricos, contaminación del aire tras la liberación de particular de polvillo, degradación del paisaje natural, afectando de manera directa los ecosistemas y las fuentes hídricas.
Respecto al abordaje desde la geografía urbana, esta ha constituido a la ciudad como su objeto de investigación asumiéndola como una unidad espacial, física y social en construcción permanente, con sus respectivas prácticas y dinámicas, las cuales arrojan como resultado el fenómeno urbano compuesto por una naturaleza multicausal propia. Al respecto, Espinosa (2009) señala que:

La realidad urbana latinoamericana, y en ella la colombiana, habla de procesos de segregación socioespacial, ya vividos por la ciudad de los llamados países centrales o "desarrollados"; de procesos de excepcional o muy rápido crecimiento urbano; de procesos de renovación urbana y, desde las ciudades, de una dinámica de transformación de las relaciones funcionales a escala regional y nacional (p. 190).

Por lo anterior, es conveniente abordar la naturaleza multicausal del fenómeno urbano y sus correspondientes conflictos socioespaciales en contextos propios. La geografia urbana contemporánea presenta debates internos a nivel epistemológico en donde discursos como los de la ecología urbana, el urbanismo marxista y el urbanismo posmoderno están en el centro del debate. Algunos de estos cuestionan el ordenamiento espacial acorde al modelo económico capitalista, en donde la discusión en torno a la justicia ambiental ha tomado relevancia en los últimos años por parte de movimientos sociales, centros de investigación y sectores espaciales.

Dentro de los debates que desde la geografía urbana han estado presentes en la agenda política, académica y social, tenemos los concernientes al emplazamiento, la morfología, la estructura espacial y social, el mercado del suelo, el uso del suelo, la planificación y el ordenamiento territorial, el derecho a la vivienda, al transporte y los problemas ambientales.

[...] la ciudad parece convocar la atención de la investigación social, debido al hecho cierto del avance inexorable del proceso global de urbanización y a un aumento sin precedentes del conflicto que en ellas se presencia por la supervivencia de grupos mayoritarios de población, cada día más excluidos 
de condiciones de existencia y reproducción social y material (Espinosa, 2009, p. 201).

De acuerdo a lo anterior, conviene recurrir a la relación naturaleza-sociedad propuesta por la geografía urbana de corte ambiental para identificar cuáles han sido los conflictos ambientales y sociales que ha generado la minería en la ciudad, en donde la historia ambiental urbana, como metodología de investigación, propicie interpretaciones actuales desde una perspectiva interdisciplinar. En síntesis, la geografia urbana brinda importantes herramientas para estudiar la ciudad y las conflictividades socioambientales generadas por la minería en Bogotá, en donde categorías como el extractivismo permiten ampliar las comprensiones económicas, ambientales y políticas que existen en el territorio.

\section{Herencia minera en la ciudad de Bogotá}

\subsection{Alfarería indígena, entre la espiritualidad y el territorio}

Desde el período Herrera, un lapso de alrededor de 16 siglos entre aproximadamente el siglo VIII a. C. y el siglo VIII d. C. (2.800 y 1.200 AP) (Herrera, 2008, p. 12), en los actuales departamentos de Cundinamarca, Boyacá y Santander, vivieron incrustados en la cordillera Oriental diferentes comunidades indígenas con importantes habilidades en la elaboración de cerámicas y en el uso de técnicas tradicionales, en donde la alfarería se constituyó en uno de sus rasgos distintivos por la gran calidad, belleza y complejidad relacionada con la gran familia de lengua chibcha, que trascendía lo material y llegaba a lo espiritual.

Sin embargo, es necesario aclarar que los procesos de aprovechamiento de dichos minerales no tenían la intencionalidad económica, lucrativa o acumulativa de riqueza; por el contrario, la finalidad consistía en suplir las necesidades básicas de los individuos o la comunidad. Ejemplo de esto fue la elaboración de artefactos para diferentes ceremonias, el ajuar funerario, las vasijas para uso doméstico y los excedentes para hacer trueques con otras comunidades indígenas.

Durante el proceso de expansión urbana agenciado por Metrovivienda en el año 2008 en la localidad de Usme - al sur de la ciudad de Bogotá-, en la hacienda el Carmen y en medio de tres afluentes hídricos, el río Fucha y las quebradas La Riquelina y Agua Dulce, se encontró una gran necrópolis prehispánica con gran cantidad de piezas de cerámica. Se estima que el nivel de densidad de entierros es alto debido al largo período en que sirvió para las comunidades indígenas, ante lo cual se requieren más de 600 años para analizar la totalidad de las piezas que reposan en el subsuelo de las cerca de 30 ha que conforman la zona de protección arqueológica.

El otro gran hallazgo también está en el altiplano. En el marco del proyecto de construcción de una estación eléctrica de transición a cargo de Codensa y las Empresas Públicas de Medellín (EPM) en inmediaciones del municipio de Soacha y el Tequendama (Cundinamarca) también se hallaron vestigios arqueológicos que datan del período Herrera.

John Alexander González Larrota, Arqueólogo responsable de la licencia otorgada por el ICANH para este rescate, explicó que "la relevancia de este hallazgo reside en la información allí contenida sobre las pautas de asentamiento, el desarrollo arquitectónico y agrícola de las sociedades que habitaron el altiplano central colombiano y, en general, sobre aspectos demográficos en tiempos prehispánicos" (Empresas Públicas de Medellín, 2016).

En los dos hallazgos se logra entrever la estrecha relación de las comunidades prehispánicas con el territorio, los bienes comunes como el agua y en particular con la tierra y los minerales que allí se configuran, como las arcillas y rocas, las cuales eran cuidadosamente modeladas para la elaboración de cerámicas y utensilios destinados para diferentes usos, convirtiéndose así en una manifestación cultural cargada de significado, sentido y pensamiento. 
Todos estos elementos de cultura material fueron empleados por los Muiscas. Su fabricación y su uso también tuvieron atributos simbólicos. Estos finalmente se integrarían como parte de los elementos necesarios para emprender los rituales propiciatorios, conmemorativos o intronizatorios, indispensables para la continuidad de la vida (Becerra, 2010, p. 13).

En esa línea de análisis, Molina (2010) es contundente al señalar la amarga relación que se empieza a entretejer durante el período colonial entre los indígenas y los europeos, en donde las relaciones de imposición y barbarie son contundentes para desarrollar el proyecto de saqueo:

En la Sabana de Bogotá se dio un encuentro cultural entre la tradición ancestral, propia de los maestros alfareros muiscas que habitaban en los actuales departamentos de Boyacá y Cundinamarca, y las técnicas de construcción que llegaron de España; aunque ese encuentro, como todos sabemos, fue impuesto por la fuerza (p. 36).

El sometimiento de la mano de obra indígena y los conocimientos que habían heredado por miles de años de sus comunidades en la alfarería y el procesamiento de arcillas fue utilizado en gran parte para la elaboración de tejas y ladrillos para ser usados por los españoles al momento de asentarse y "fundar" la ciudad de Santafé.

\subsection{La herencia minera durante la Colonia en Santafé}

Durante el período colonial y los inicios de la república se usaron otros materiales para la construcción de viviendas y edificaciones, cuya base eran las rocas y el procesamiento de arcillas que se encontraban a lo largo de los cerros Orientales de Bogotá. Otra de las materias primas utilizadas por la época fue la madera, cuyo uso fue intensificándose con el paso del tiempo como producto del aumento de la demanda para la cocción de los alimentos, la construcción de estructuras y la cocción de arcillas con las cuales se elaboraban ladrillos y tejas de regular calidad. No es gratuito observar en fotografias antiguas de los cerros de Bogotá (hasta mediados del siglo xx) que se encuentran completamente deforestados. Según Martínez (1976, citado por Molina, 2010),

Los cerros los abastecían de los materiales necesarios para construir sus viviendas (con técnicas españolas), como la piedra caliza, que quemada al aire libre se transformaba en cal; la arena de peña, que mezclada con la cal generaba morteros de pega; la piedra de labor para reforzar cimientos y muros; las maderas duras para la estructura de muros y cubiertas; la leña para los chircales, las herrerías, las fundiciones y las cocinas; y por supuesto, la generosa arcilla, a partir de la cual se fabricaban, en los chircales, tablones, ladrillos y tejas de barro cocido además de adobes secados al sol (p. 35).

En contraposición, la ciudad de esa época no superaba las 100 ha de extensión territorial - concentrándose en la actual localidad de La Candelaria-y era el epicentro de los poderes económicos, políticos y religiosos. En el resto del territorio, la "potrerización" de la sabana y la explotación de yacimientos de arcillas, rocas y arenas fueron procesos paralelos que complementaban la economía colonial. La gran síntesis a la cual llega Molina (2010) es la estrecha relación que existe entre las características geológicas del subsuelo, la mano de obra indígena y las intencionalidades de las élites coloniales:

La ciudad colonial se hizo realidad gracias a las piezas cerámicas fabricadas en los chircales de los cerros Orientales, con la arcilla de sus laderas, la leña de sus bosques y el trabajo de sus alfareros. Durante la Colonia los alfareros muiscas y sus descendientes hicieron a mano millones de piezas cerámicas para construir la ciudad (p. 56).

Es así como la herencia minera de la ciudad de Bogotá se remonta a aquellos años de la Colonia en donde la imposición fue la constante, si bien se prolongó históricamente en el territorio después del proceso 
independentista del siglo XIX. En esa medida, Molina e Hinojosa de Parra (2011) mencionan la existencia de hornos para cocinar ladrillos desde mediados de 1831, compactos y horneados a altas temperaturas, en donde se usaba carbón mineral y maderas.

La gran fractura histórica en la construcción de vivienda y estructuras en la ciudad de Bogotá está en el proceso de modernización e incipiente industrialización que atravesó el país a inicios del siglo xx, en donde los pilares iniciales giraron en torno a la tecnificación y el mejoramiento del espacio urbano, razón por la cual el uso de materiales de construcción como el cemento hacen su aparición para el año de 1909 a cargo de la Compañía de Cementos Samper, en donde la influencia del pensamiento europeo y norteamericano en torno a la higiene, el confort y el clasismo, unido a procesos técnicos y tecnológicos, posibilitó nuevas maneras de entender lo urbano.

En medio del proceso de modernización y crecimiento de la economía nacional, los hijos del empresario y político liberal Miguel Samper Agudelo propusieron a la municipalidad proveer de energía eléctrica a la capital por medio de una planta hidroeléctrica ubicada en la hacienda El Charquito, en inmediaciones de Soacha y el salto del Tequendama, intentando replicar los avances técnicos y tecnológicos que vivía Europa tras la Revolución Industrial. Una vez recibieron los correspondientes permisos administrativos, los señores Samper Brush viajaron a Europa para contratar ingenieros, técnicos y empresas que asumieran la responsabilidad de construir la hidroeléctrica. $\mathrm{Al}$ respecto, Carrasco Zaldúa (2006) señala:

El cemento era transportado en barriles de madera revestidos con materiales que impedían el deterioro por la humedad, y exteriormente reforzados por cintas de alambre y bandas de acero para evitar daños durante el transporte (p. 27).

La fábrica de Cementos Samper instaló su sede principal en el sector de Sans Façon, en la calle 13 con carrera 17, cerca de la estación del ferrocarril.
Allí se procedió a montar un primer horno vertical del tipo llamado "de botella", los molinos, talleres y el motor eléctrico de 15 HP para mover la maquinaria. Ésta había sido solicitada a Inglaterra, despachada por vapores desde Jamaica por los distribuidores Charles Lavy \& Co. Ltd. de Londres (Carrasco Zaldúa, 2006, pp. 30, 31).

Es importante mencionar que la calidad del cemento producido era baja. Sin embargo, con el paso de los años se fue tecnificando, mejorando y ampliando la oferta de productos para la construcción, razón por la cual llegaron otras inversiones económicas para fortalecer la Compañía de Cementos Samper. Con el mejoramiento de la industria del cemento, la ciudad tomó un giro urbanístico diferente y sirvió de base para nuevas edificaciones de gran altura, consolidando así la estructura de hormigón (cemento, grava, piedra y agua), sumado al importante número de construcciones que el Ministerio de Obras Públicas realizó en el marco de la conmemoración del Centenario de la Independencia de Colombia. Así mismo, es de vital importancia reconocer que el proceso de formación urbana de Bogotá no fue homogéneo ni mucho menos planificado por el Estado.

\subsection{Los chircales en la ciudad y el proyecto modernizador}

En ese proceso de urbanización y parcelación, tenemos la hacienda Tunjuelo, de gran extensión desde la Colonia, en donde se cultivaba trigo, cereales y se criaban especies menores de ganado. Es importante mencionar la composición física de los suelos, que eran muy arcillosos como producto del régimen de lluvias y la cercanía a la cuenca hídrica del río Tunjuelo. Dicha hacienda fue fragmentada y parcelada desde la década de los cuarenta y dio origen a nuevos asentamientos urbanos en los bordes de la carretera que unía Usme con Bogotá, que carecían de agua potable, vías y equipamientos educativos. Es importante aclarar que el proceso de parcelación de dichas tierras 
fue agenciado por actores privados, sin acompañamiento o regulación del sector público.

$\mathrm{Al}$ respecto, Zambrano (2004) señala que las intervenciones en la cuenca alta del río Tunjuelo concretadas en el embalse La Regadera generaron condiciones idóneas para la parcelación de importantes sectores de la cuenca media del Tunjuelo, su consiguiente urbanización y la extracción de material pétreo:

[...] facilitó la explotación de materiales de construcción, tales como gravilla, gredas y arena, cuya demanda se había incrementado por el crecimiento acelerado de Bogotá desde los años treinta. Es durante los años cuarenta que se instalan la fábrica Alemana de Ladrillos, en cercanía al barrio Meissen (p. 88).

Las décadas de los cincuenta y los sesenta fueron neurálgicas para el país e indudablemente para la ciudad debido a que en las áreas rurales — principalmente en departamentos como Boyacá, los Santanderes, Cundinamarca, los Llanos Orientales, Tolima y el Valle del Cauca - la Violencia bipartidista entre liberales y conservadores arrasaba con pueblos, veredas y caseríos en donde las prácticas de muerte, terror y barbarie fueron los factores que marcaron los más de 20 años que duró este periodo. Torres (1993) señala que las décadas de los cincuenta y los sesenta son muy importantes para el crecimiento demográfico de la ciudad de Bogotá:

En el plano demográfico, Colombia sufre un aumento poblacional acelerado desde 1930, alcanzando entre 1951 y 1964 su máximo grado de crecimiento. Simultáneamente vive una intensa concentración urbana, dejando de ser un país eminentemente rural a comienzos del siglo para convertirse en un país cuya población urbana actual constituye más de las tres cuartas partes del total (p. 19).

El abrupto cambio demográfico, ligado a la concentración de la población en las grandes ciudades, se convierte en generador de nuevas conflictividades y reivindicaciones socioespaciales debido a que los conflictos en el campo han estado relacionados con el uso y la tenencia de la tierra, mientras en las ciudades los conflictos giran en torno a la adquisición de terreno para la construcción de vivienda, suministro de servicios públicos, búsqueda de empleo y equipamientos culturales.

En esa medida, en los actuales barrios de Las Cruces, Las Brisas, Girardot, Ramírez, Tunjuelito, Meissen, Santa Lucia, San Vicente, San Carlos, San Benito, Usme, La Picota, Chircales, Molinos, Altamira, Camino de Oriente e inmediaciones al 20 de Julio se fueron configurando y consolidando los chircales, entendidos como unidades de producción de ladrillo de manera artesanal en las cuales eran empleadas familias completas provenientes de las áreas rurales, quienes no tenían un salario definido y trabajan en las parcelas de los hacendados en toda la línea de producción del ladrillo. El proyecto modernizador de la ciudad terminó convirtiéndose en la representación de

[...] la "ciudad precaria y excluyente", se observa en la siguiente figura el caso del desarrollo marginal en Bogotá, fenómeno localizado tanto en el interior de la ciudad, en áreas constituidas por edificios vetustos del centro histórico, como en zona alejadas y mal comunicadas, donde se han extendido los denominados "barrios de invasión", áreas caracterizadas de manera inexacta desde la planificación urbana como “zonas subnormales” (Rivera Pabón, 2016, p. 165).

$\mathrm{Al}$ respecto, Martha Rodríguez y Jorge Silva, entre 1966 y 1971, realizaron la producción del documental Chircales, en el cual caracterizan las condiciones laborales de los trabajadores acompañadas de impactantes imágenes en blanco y negro, en donde el paisaje árido y solitario del suroriente de la ciudad contrasta con los testimonios de la familia Castañeda -Alfredo, María y sus 12 hijos-, todos campesinos con rasgos indígenas, quienes denuncian la dureza del trabajo, las jornadas laborales de más de 12 horas, las amenazas constantes sobre posible despido y los bajos salarios que reciben por parte de su patrón.

El obrero desalojado por la miseria y la violencia política traslada su estatus de siervo bajo un amo del 
latifundio agrario al latifundio urbano. En manos de un señor terrateniente respaldado bajo un régimen, los chircales escapan de todo control laboral o estadístico (Rodríguez \& Silva, 1971).

Las condiciones laborales de los obreros están determinadas por salarios a destajo, es decir, dependen del nivel de producción mensual, donde el hombre junto con su mujer e hijos constituyen la unidad económica de producción. El obrero no posee ni los medios de producción ni el producto final de su trabajo, es un obrero que recibe un pago semanal o mensual a destajo y es sometido a una total explotación en donde no existe seguridad social ni agremiación sindical que vele por sus derechos en esta labor que es su única posibilidad de empleo, condiciones que se mantuvieron hasta finales del siglo xx en los chircales y las ladrilleras del suroriente de la ciudad.

En el año 2002 se realizó un proceso de caracterización de los chircales en la localidad de Rafael Uribe Uribe en donde el rol de los niños y jóvenes es el centro de la investigación y se destacan las continuidades en torno a las precarias condiciones de trabajo de los niños, jóvenes y adultos. Es importante tener en cuenta que

[...] los niños se dedican a: cargar agua, cargar y descargar carretilla, encarar, amontonar y remojar tierra, retirar, y acercar los ladrillos y el carbón del horno (Empresa Nacional Minera [Minercol] \& Cruz Roja Colombiana, 2002, p. 23).

Paralelo a los chircales, se fueron configurando y expandiendo las fábricas de ladrillo o "ladrilleras", caracterizadas por realizar procesos de producción de ladrillo más tecnificados y diversos a escala industrial. Ladrilleras como Santafé y la Alemana ganan espacios, se empiezan a apoderar del negocio del ladrillo y paulatinamente aumentan el número de producción de ladrillos macizos y bloques huecos, los cuales fueron esenciales para la creciente demanda de materiales de construcción que requería la ciudad en su proceso de expansión urbana y construcción de vivienda legal, ilegal y "pirata".
Es importante señalar que tanto los chircales como las ladrilleras se constituyeron como importantes centros de producción y empleo de poblaciones analfabetas, carentes de educación y formación profesional, muchos de los cuales eran desplazados por la violencia. Dentro de las denuncias a las ladrilleras en materia ambiental se encuentra la expulsión de dióxido de carbono por la quema excesiva de carbón en el proceso de cocción de los ladrillos al interior de los grandes hornos que pueden estar varios días a temperaturas que superan los $700{ }^{\circ} \mathrm{C}$, lo cual genera emisiones de carbono contaminante a la atmósfera y afecciones pulmonares y respiratorias para trabajadores y habitantes del sector. Así mismo, la remoción en masa generó perdida de capa vegetal e inestabilidad en el terreno.

\subsection{Extractivismo minero en Bogotá: el caso de los parques minero-industriales del sur de la ciudad}

Este apartado se relaciona con el entramado económico, territorial y social de la minería en la ciudad, razón por la cual conviene pensar en por qué hablar de extractivismo minero en Bogotá. Para esto se abordan las dinámicas espaciales y económicas que las empresas mineras han tenido en el territorio, donde los planteamientos de Göbell y Ulloa (2014), respecto a la categoría de extractivismo son los siguientes:

[...] un modo de producción a gran escala, orientado preferentemente a la exportación, e implica la instalación de un enclave transnacional en áreas periféricas. Esto requiere de conocimientos y tecnologías específicas y se basa en el desarrollo de infraestructura (vivienda, transporte, energía, etc.) $\mathrm{y}$ de determinados marcos legales y financieros. El Estado, tanto en sus niveles nacionales como sub-nacionales, tiene un particular interés en este modo de producción, debido a los ingresos fiscales y a las dinámicas de crecimiento económico que permite 
generar, pero por lo general no toma en cuenta los costos ni los riesgos ambientales y sociales que implica. Esto responde a una visión de desarrollo que privilegia lo económico en un sentido de acumulación de riqueza (p. 15).

Para el análisis de la minería en Bogotá se propone asumir algunos de los elementos propuestos por las investigadoras Göbel y Ulloa (2014) que permiten realizar un estudio de caso sobre los parques minero-industriales, en donde se identifican algunos elementos que hacen parte de las economías extractivistas como la presencia de marcos jurídicos y legales al servicio del capital privado y extranjero, los cuales permiten o dan vía libre al desarrollo de la minería en el territorio. Adicional a ello, la instalación de un enclave transnacional en áreas periféricas resulta fundamental para comprender el componente territorial y geoestratégico en donde las empresas participan en complicidad con el Estado para el desarrollo de dichas actividades económicas, en las cuales prevalece el beneficio privado sobre el ambiental y colectivo, generando consigo un ciclo de acumulación de capital versus la prevalencia de conflictos socioambientales.

Esbozados los anteriores ejes de trabajo, se procede al análisis de algunos de los marcos legales que regulan la minería en Colombia y en Bogotá y que son un pilar clave de la economía del país. En el marco de la naciente Constitución Política de 1991, se realizaron reformas sustanciales a la jurisdicción ambiental del país con el objetivo de gestionar y regular las actividades mineras por medio de la Ley 99 de 1993 o ley del medio ambiente, la cual crea el Ministerio de Medio Ambiente

[...] como organismo rector de la gestión del medio ambiente y de los recursos naturales renovables, encargado de impulsar una relación de respeto y armonía del hombre con la naturaleza y de definir, en los términos de la presente ley, las políticas y regulaciones a las que se sujetarán la recuperación, conservación, protección, ordenamiento, manejo, uso y aprovechamiento de los recursos naturales renovables y el medio ambiente de la Nación a fin de asegurar el desarrollo sostenible.

En esa medida, también se regulan los mecanismos legales y técnicos que posibilitan la actividad minero-energética en el territorio nacional por medio del trámite de licencias ambientales, delimitación de áreas aptas para la minería, obtención de títulos mineros y responsabilidades ambientales de las personas naturales o las compañías que se dedican a la actividad extractiva y la transformación.

Además, se declara 'la Sabana de Bogotá, sus páramos, aguas, valles aledaños, cerros circundantes y sistemas montañosos como de interés ecológico nacional, cuya destinación prioritaria será la agropecuaria y forestal" en el artículo 61 de la Ley 99 de 1993 de recursos naturales, que "blinda" los ecosistemas de la ciudad de Bogotá ante el desarrollo de actividad minera y extractiva gracias a las características geomorfológicas y el potencial hídrico y ambiental del ecosistema, destinando el suelo para la producción agrícola. Adicional a ello, por medio de la Resolución 222 de 1994 se reglamenta que la entidad encargada de regular las zonas aptas para la delimitación de los polígonos mineros es el Ministerio de Medio Ambiente, que "determinará las zonas en las cuales exista compatibilidad con las explotaciones mineras, con base en esta determinación la Corporación Autónoma Regional de Cundinamarca -CAR- otorgará o negará las correspondientes licencias ambientales".

En medio de ese panorama legislativo de "control" institucional para conservar los diferentes ecosistemas y el ambiente, surgen ciertas irregularidades y contradicciones prácticas de parte del Ministerio de Ambiente, la Corporación Autónoma de Regional de Cundinamarca y la Agencia Nacional de Licencias Ambientales, quienes establecen de manera legal varios polígonos para la extracción de materiales para la construcción, como arenas, arcillas, rocas, derivados pétreos y gravillas, argumentando que el potencial del subsuelo del territorio es apto para suministrar materias primas para el sector 
de la construcción, teniendo en cuenta el aumento en la demanda de la industria.

También con el objetivo de regular, controlar y disminuir los impactos ambientales de las canteras y fábricas artesanales procesadoras de materiales para la construcción, el Distrito decidió crear una política de ordenamiento territorial, suscrita mediante el Decreto 619 de 2000 con el cual se configuró el Plan de Ordenamiento Ambiental y Territorial. Por medio de este decreto se crea la figura de los parques minero-industriales, los cuales son concebidos como

[... zonas en donde se permite desarrollar de manera transitoria la actividad minera, aprovechando al máximo sus reservas bajo parámetros de sostenibilidad ambiental. Constituyen zonas estratégicas para el desarrollo del Distrito, por ser las áreas que concentran los puntos de extracción de materiales necesarios para la construcción de la ciudad. De su manejo, control y seguimiento depende en gran medida el comportamiento económico del sector de la construcción.

Como resultado de esos procesos de concertación con personas naturales y empresas privadas nacionales y transnacionales, cooperativas y demás agremiaciones, se crearon dos parques minero-industriales (PMI), los cuales están localizados al sur de la ciudad y cuyas licencias ambientales para la extracción oscilan entre los 20 y los 30 años. Los PMi son Mochuelo (Ciudad Bolívar) y Tunjuelito; para el año 2003 se adjudicó un tercer PMI en Usme (Figura 1). Dichos PMI son operados por empresas privadas de carácter nacional e internacional como Holcim, Cemex y la Fundación San Antonio (adscrita a la Arquidiócesis de Bogotá), algunas asociaciones de pequeños empresarios y sociedades anónimas. Es importante mencionar que estos tres PMI funcionan legalmente por los aportes económicos o regalías derivadas de la venta de materiales de construcción en la ciudad que giran al Distrito.

Mediante el Decreto 469 de 2003 "por el cual se revisa el Plan de Ordenamiento Territorial de Bogotá D.C." queda estipulado que las entidades distritales que se encargarán de regular y supervisar los procesos de explotación minera y el manejo ambiental y social son: el Departamento Administrativo de Planeación Distrital (DAPD), el Departamento Técnico Administrativo del Medio Ambiente (DAMA), actual Secretaría Distrital de Ambiente, el Ministerio de Ambiente y la Corporación Autónoma de Cundinamarca (CAR). Algo preocupante es que a pesar de que estas instituciones sean las encargadas de regular la minería en la ciudad, cerca del 92\% de la minería en Bogotá y en municipios de Cundinamarca es de carácter ilegal, ahondando aún más los conflictos socioambientales (Portafolio, 2012).

Lo anterior también demuestra la falta de efectividad en las pretensiones de focalizar, regular y controlar la actividad minera en polígonos determinados legalmente por medio de los PMI, mientras se mantienen otras expresiones de extracción como las canteras y las ladrilleras, que generan importantes daños ambientales y no pagan regalías. En un informe de la Personería de Bogotá, esta entidad hace un llamado a la Secretaría Distrital de Ambiente sobre esta situación. Así lo divulgó el periódico Portafolio en 2012:

El ente de control informó que de 108 empresas mineras que operan en la ciudad, 100 funcionan en la ilegalidad; 88 no tienen ningún papel soporte de actividad, 12 los tienen incompletos y solo 8 canteras tienen los documentos en regla para su funcionamiento. Las autoridades reportaron la existencia de 39 canteras en la Localidad de Usme, 28 en Ciudad Bolívar, 17 en Rafael Uribe Uribe, 13 en San Cristóbal, 10 en Usaquén y una en Santa Fe.

En promedio, son 98 las canteras ilegales que operan al sur de la ciudad y 10 más en los cerros de Usaquén. Sin lugar a dudas es una situación muy problemática por cuanto los daños ambientales y sociales son de gran envergadura, tales como remoción en masa, deforestación, pérdida de biodiversidad, perforación, pérdida de cuerpos de agua subterránea y polución, entre otros que generan pasivos ambientales que no son asumidos por ninguna entidad o persona 
natural. Es muy importante señalar que estos impactos ambientales no son generados únicamente por la minería ilegal; bajo otras intensidades, la minería legal genera impactos que se supone deberían ser asumidos por medio de planes de manejo ambiental con criterios técnicos capaces de promover la rehabilitación del terreno, ya que esa es la contraprestación de las empresas con el Distrito y el ambiente.

La paradoja de la minería en la ciudad de Bogotá es que no ha generado beneficios colectivos más allá de extraer y transformar materias primas para la construcción y el enriquecimiento del capital privado $\mathrm{y}$ transnacional y, por el contrario, ha deteriorado $\mathrm{y}$ modificado el ecosistema, agudizando en esa medida las tensiones sociales entre las comunidades - directamente afectadas por la actividad minera- y las empresas que se benefician de los procesos de extracción, donde se envuelve el deterioro acelerado de las viviendas, vías principales y secundarias de los barrios aledaños al [PMI], amenazas y señalamientos por parte de actores armados hacía los líderes sociales y ambientales que se oponen a la minería en la localidad, afectaciones en la salud respiratoria de los habitantes y pérdida de espacios de socialización ante la negativa de construir un parque ambiental en las zonas de presencia minera.

LOCALIZACIÓN DE LOS PMI EN LA CIUDAD DE BOGOTÁ D.C

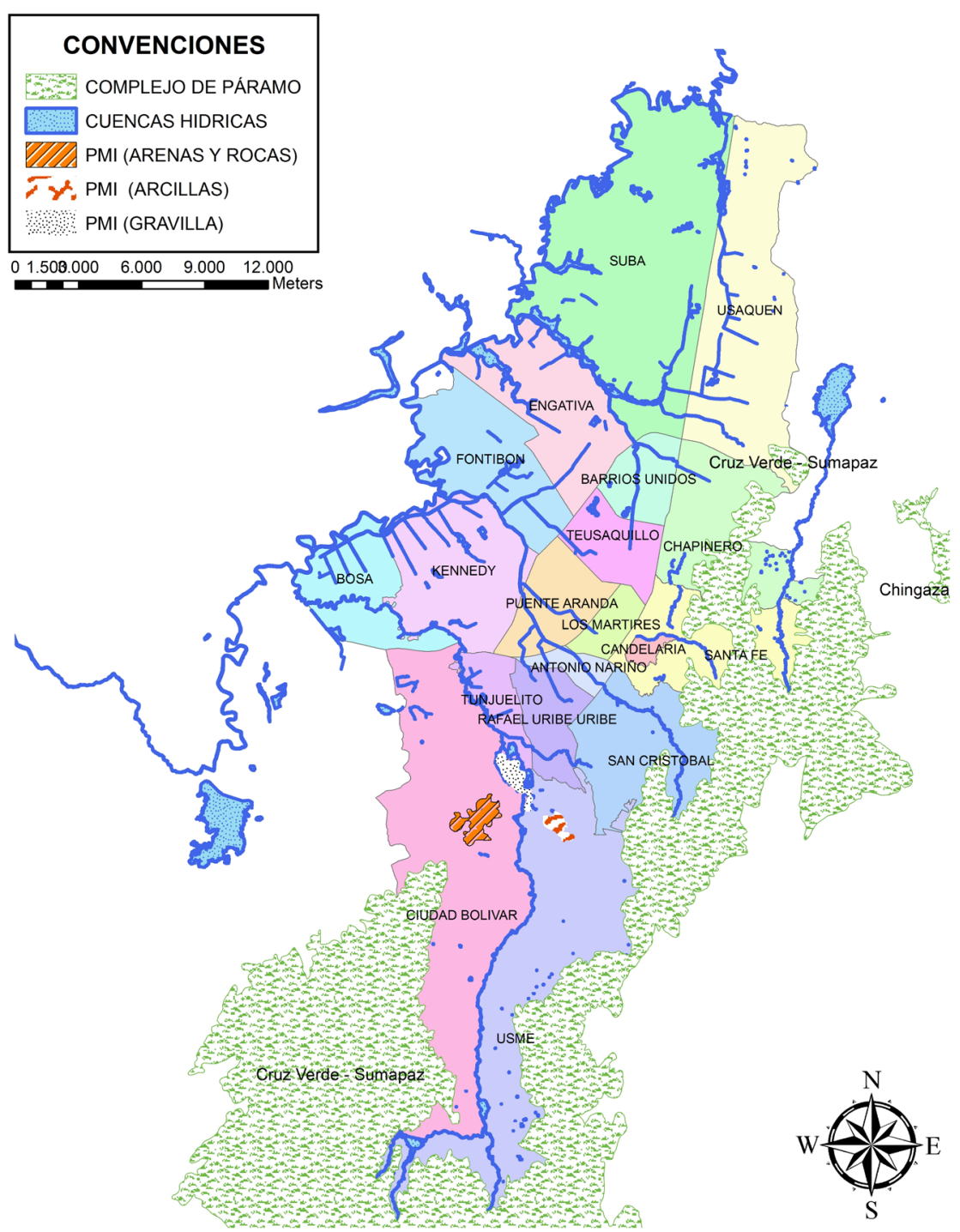

FIGURA 1. Mapa con la localización de PMI en la ciudad de Bogotá FUENTE: elaboración propia. 


\subsubsection{Caracterización del PMI Tunjuelo}

Es importante caracterizar de forma concreta los impactos sociales y ambientales que la actividad minera ha causado en los ecosistemas del sur de Bogotá. En primera medida, en la zona de operación del PMI del Tunjuelo hay antecedentes que se remontan a 1945, cuando la empresa Cementos Samper inició actividades a lo largo de la ronda del río Tunjuelo con la extracción de gravas. Sin embargo, a lo largo de más de 60 años el río ha tenido cuatro intervenciones en su ronda para optimizar la actividad minera, las cuales han sido periodizadas por diferentes investigadores de la siguiente manera:

1. 1952-1969: corte de un meandro.

2. 1969-1971: corte de un meandro en zona de la concesión de la Fundación San Antonio (actual mina Sánchez González).

3. 1971-1976: rectificación del río por un tramo de $1 \mathrm{~km}$.

4. 1998: permisos otorgados por la CAR a la empresa Cementos Diamante s. A. mediante la Resolución 200 del 12 de febrero de 1998 para el corte de un meandro.

Como resultado de dichas intervenciones en la ronda del río, la localidad de Tunjuelito ha tenido repetidas inundaciones desde mediados de los años noventa y los principales afectados han sido los habitantes del sector, quienes en épocas de lluvias ven cómo las aguas del caudal copan los espacios de sus viviendas. El episodio de mayor impacto ocurrió en el año 2002, cuando el nivel del río creció de 1,5 metros de altura y, como medida para contener el caudal, el Acueducto de Bogotá decidió romper los jarillones construidos por las empresas mineras para delimitar el río con las cárcavas dejadas por la extracción de materias primas.

Como consecuencia de esa peripecia, cerca de 25 millones de metros cúbicos de agua fueron al fondo de las cárcavas de más de 40 metros de profundidad.
Aunque se pudo contener el alto nivel de agua, lo cierto es que esta quedó estancada y generó problemas de salubridad que afectaron directamente a la población y las dinámicas laborales de las empresas, las cuales decidieron interponer una demanda al Distrito por cerca de 400.000 millones de pesos.

Lo cierto del asunto es que la actividad extractiva de minerales en las riberas del río Tunjuelo ha afectado la estructura ecológica principal del sur de la ciudad, por cuanto la extracción de materiales de arrastre y vega propios de la formación geológica ha alterado el orden del suelo, el subsuelo y sus potencialidades para filtrar y regular el agua. Al respecto, De Roux señaló que:

Las llanuras aluviales se caracterizan por ser las áreas con el mayor potencial agro-ecológico, por la acumulación de sedimentos ricos en nutrientes y por las condiciones de humedad relacionadas con niveles freáticos (niveles de agua subterránea) cercanos a la superficie. Estos suelos han sido removidos y perdidos irreversiblemente por la actividad minera, y son más escasos aún por encontrarse cubiertos por pavimento en casi todo el resto del territorio urbano (Apuesta por la Ciudad, 2009).

Indudablemente el daño es irreversible debido a la intensiva actividad minera y a las desviaciones que ha tenido, razón por la cual se han perdido las llanuras de inundación en la cuenca media del Tunjuelo, espacio en el cual el río se ensancha, pierde velocidad y crea nuevos meandros para mejorar su capacidad hidráulica. Además de las desviaciones y las pérdidas de espacio que ha tenido el Tunjuelo, De Roux señaló que el problema es más complejo debido a que

[...] los taludes que quedan tras las extracciones de las gravas y arenas pueden fallar en cualquier momento y generar emergencias como la de mayo de 2009, cuando dos millones de metros cúbicos de tierra cayeron sobre el barrio Villa Jackie (Apuesta por la Ciudad, 2009).

Dichos sucesos ocurrieron a lo largo de la noche del 20 de mayo de 2009 en inmediaciones al polígono de extracción a cargo de Cemex. Aunque no se presentaron 
personas heridas de gravedad o muertos por los sucesos, sí se presentaron pérdidas materiales en más de 90 predios, razón por la cual la Dirección de Prevención y Atención de Emergencias de Bogotá (DPAE) declaró la alerta naranja de evacuación preventiva para los habitantes; además de ello, la empresa no dejó de operar y continúo con sus trabajos de extracción. El proceso de concertación entre la empresa y la comunidad afectada tuvo el acompañamiento de la Defensoría del Pueblo y la Contraloría, proceso en el cual la empresa compró los predios del barrio Villa Jackie a precios cuestionables, los afectados no quedaron del todo satisfechos y el espacio de intervención de la empresa aumentó.

Otros de los impactos sociales y ambientales que ha generado el PMI del Tunjuelo están relacionados con la indudable disminución de la calidad paisajística del entorno, disminución de la vida útil de las vías aledañas al PMI por el tránsito de vehículos pesados de las empresas, pérdida de recurso biótico, contaminación irreversible de acuíferos y aguas superficiales, riesgo de remoción en masa de los taludes mineros en un eventual sismo en la ciudad, cambios del microclima y generación de pasivos ambientales que deben ser asumidos por las empresas mineras que operaron en dichos lugares.

Aunque en el marco normativo existe la figura de plan de manejo ambiental, el cual es asumido por las empresas al momento de realizar procesos de extracción de minerales del subsuelo para cerrar el ciclo de explotación minera de manera sustentable, esto deja más preguntas que certezas debido a que las acciones antrópicas en los territorios alteran la estructura ecológica principal, generando desajustes irreversibles debido a que han sido sustraídos y alterados los ciclos de la naturaleza. En las siguientes fotografías aéreas se pueden identificar las diferentes intervenciones que ha tenido la ronda del río Tunjuelo a lo largo del siglo xx.

\subsubsection{PMI El Mochuelo}

El PMI El Mochuelo está ubicado en la localidad de Ciudad Bolívar. Sus particularidades residen en el título minero 16.432 a cargo de la CAR que fue adjudicado el 9 de enero de 1998 con vigencia hasta el 8 de enero de 2028, debido a que dichos predios se encontraban en el área rural. Se caracteriza por ser el de mayor extensión, con 1.877 ha de las cuales se extraen rocas areniscas y arenas.

Los conflictos socioambientales que se logran identificar en la zona son: asentamientos informales en los bordes del polígono minero, pérdida del suelo agroecológicamente productivo, cambio del uso del suelo, pérdida y contaminación de cuerpos hídricos que genera desajustes estructurales al ecosistema subxerofítico, en un área caracterizada por ser espacios con poca precipitación en donde predomina la vegetación de arbustos de mediano tamaño.

Algunas de las tensiones a nivel social que ha generado el PMI en Ciudad Bolívar están ligadas a la cercanía de los polígonos de extracción a barrios y veredas en donde las poblaciones se han visto afectadas por enfermedades respiratorias, pérdidas de afluentes hídricos y de suelo con potencial para la agricultura, así como daños en la malla vial. Aunque en el momento en que fue adjudicado el polígono minero estaba en el área rural, en la actualidad la localidad ha crecido de manera exponencial hasta tal punto de compartir espacios con las empresas mineras. Otra particularidad del PMI es que se encuentra en límites con el municipio de Soacha, lo cual genera problemas por linderos y polígonos mineros.

\section{Conclusiones}

El presente escrito es el resultado de un proceso de revisión documental en el cual se identificó el deterioro ambiental generado por la minería y su relación con las comunidades en la ciudad de Bogotá. El estudio se centró en el suroriente de la ciudad. Algo a destacar son los antecedentes desde el período colonial sobre dinámicas de extracción de minerales para la construcción de edificaciones, lo cual fue denominado "la herencia minera". El proceso de modernización de 
la ciudad iniciado a mediados del siglo xx, unido a la aparición de las primeras industrias y fábricas procesadoras de materias primas para la construcción, como las que producen ladrillos y cemento, determinó los ejes de desarrollo y crecimiento urbanos.

En esa medida, las actuales localidades de la ciudad como Usme, Ciudad Bolívar, Tunjuelito, San Cristóbal, Rafael Uribe y Usaquén - las cuales eran grandes haciendas o municipios alejados del casco urbanohan sido polígonos mineros que desde hace más de 70 años ha abastecido la constante demanda de materias primas para la construcción, como arenas, rocas, gravas y arcillas. Es importante mencionar en que el proceso de investigación se establecieron otras periodizaciones y características de las dinámicas extractivas de la minería, las cuales transitan de la producción artesanal y rústica en los chircales a una con mayor sofisticación técnica como las ladrilleras, las cuales tuvieron gran relevancia hasta entrado el siglo XXI.

Sin embargo, el punto de inflexión histórica y productiva es la década de los noventa, en la cual diferentes entidades gubernamentales y ambientales, bajo la premisa de regular la extracción de materias primas, crearon la figura de los PMI, los cuales se han consolidado como polígonos mineros dentro del área urbana de Bogotá, en donde el capital transnacional y privado se ha consolidado. Este aporte teórico sobre el desarrollo histórico de la minería en la ciudad fue posible gracias a la implementación de algunas herramientas de la historia ambiental urbana, la cual se ha ido constituyendo en una metodología de investigación que permite comprender la realidad ambiental y espacial desde una perspectiva histórica, si bien el estudio sobre las dinámicas mineras desde esta perspectiva aún es incipiente.

Para finalizar, el problema de la minería gana espacios en la sabana y las autoridades competentes no han sido eficientes en su control y regulación. Si no se regula la construcción de vivienda y se amplía la demanda de materias primas, la minería estará latente en el paisaje de la ciudad y de la sabana de Bogotá. El debate y las disputas están abiertas.

\section{Referencias}

Apuesta por la Ciudad (2009, agosto 28). Minería en los antejardines: el caso del Tunjuelo. http://www.carlosvicentederoux.org/index.shtml?apc $=r-x x-1-\& x=6655$

Becerra, J. V. (2010). Arte y alfarería Muisca. Ancestros prehispánicos de Bogotá. Departamento de Antropología, Universidad Nacional de Colombia.

Carrasco Zaldúa, F. (2006). La Compañia de Cemento Samper. Trabajos de arquitectura 1918-1925. Planeta.

Decreto 619 de 2020 (julio 28), por el cual se adopta el Plan de Ordenamiento Territorial para Santa Fe de Bogotá, Distrito Capital.

Empresa Nacional Minera (Minercol) \& Cruz Roja Colombiana (2002). Coloreando el chircal. Minercol.

Empresas Públicas de Medellín (2016, julio 30). Uno de los más importantes hallazgos arqueológicos del país. http:// www.epm.com.co/site/Home/SaladePrensa/BoletinesEstamosAhi/EPMfinaliz $\% \mathrm{C} 3 \%$ B3elrescatedelhallazgoarqueol\%C3\%B3gicoenNuevaEsperanza. aspx

Espinosa, M. (2009). Perspectiva de la geografía crítica en el estudio de la ciudad colombiana contemporánea. En J. W. Montoya (ed.), Lecturas en teoría de la geografia (pp. 198-234). Universidad Nacional de Colombia.

Göbel, B. \& Ulloa, A. (2014). Extractivismo minero en Colombia y América Latina. Universidad Nacional de Colombia.

Herrera, M. (2008). Milenios de ocupación en Cundinamarca. En J. A. Gamboa (comp.), Los muiscas en los siglos XVI y XVI: miradas desde la arqueología, la antropología y la historia (pp. 1-33). CESO, Ediciones Uniandes.

Ley 99 de 1993 (diciembre 22), por la cual se crea el Ministerio del Medio Ambiente, se reordena el Sector Público encargado de la gestión y conservación del medio ambiente y los recursos naturales renovables, se organiza el Sistema Nacional Ambiental, SINA, y se dictan otras disposiciones. Diario Oficial n ${ }^{\circ}$ 41.146.

Ministerio de Medio Ambiente (1994, agosto 3). Resolución 222, por la cual se determinan zonas compatibles para las explotaciones mineras de materiales de construcción en la Sabana de Bogotá y se dictan otras disposiciones.

Molano, F. (2019). La historia ambiental urbana: contexto de surgimiento y contribuciones para el análisis histórico de la ciudad. Anuario Colombiano de Historia Socialy de la Cultura, 43, 375-402. 
Molina, L. (2010). Alfarería y urbanismo. Los chircales de Santafé (hoy Bogotá) y su impronta en la arquitectura y el desarrollo urbano de la ciudad colonial. Revista Nodo, 8(4), 31-58.

Molina, L. F. \& Hinojosa de Parra, R. (2011). De la mampostería colonia al ladrillo a la vista. Revista Nodo, 5(10), 91-112.

Portafolio (2012, noviembre 4). El 92,6\% de la minería en Bogotá es ilegal. Portafolio. http://www.portafolio.co/ economia/finanzas/92-mineria-bogota-ilegal-98896

Preciado,J., Leal, R., \& Almanza, C. (2005). Historia ambiental de Bogotá, siglo Xx: elementos históricos para la formulación del medio. Universidad Distrital Francisco José de Caldas.

Rivera Pabón, J. A. (2016). Análisis geo-histórico del proceso de urbanización en América del Sur: de la ciudad indoamericana a la ciudad neoliberal. Perspectiva Geográfica, 1(21), 151-178. https://revistas.uptc.edu. co/index.php/perspectiva/article/view/4581/3854
Rodríguez, M. \& Silva, J. (Dirección) (1971). Chircales. [Película].

Sánchez-Calderón, V. \& Blanc, J. (2019). La historia ambiental latinoamericana: cambios y permanencias de un campo en crecimiento. Historia Crítica, 74, 3-18. https://doi.org/10.7440/histcrit74.2019.01

Torres Carrillo, A. (1993). La ciudad en la sombra: barrios y luchas populares en Bogotá 1950-1977. Cinep.

Vega, R. (2014, agosto 18). Extractivismo, enclaves y destrucción ambiental. https://rebelion.org/extractivismo-enclaves-y-destruccion-ambiental/

Zambrano Pantoja, F. (2004). Historia de la localidad de Tunjuelito. El poblamiento del Valle Medio del Río Tunjuelo. Editora Guadalupe Ltda. 